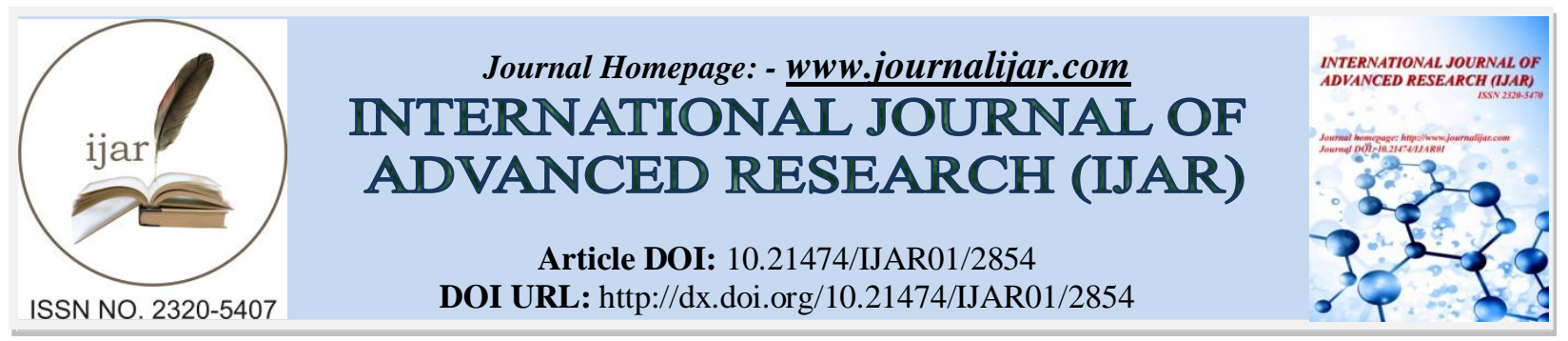

RESEARCH ARTICLE

\title{
AN AUTOPSY BASED COMPARATIVE STUDY OF PATTERN OF INJURIES IN PEDESTRIANS INVOLVED IN RAILWAY TRACK DEATHS.
}

Dr. VALSALA. K, Dr. C. S SREEDEVI and Dr. SREELEKSHMI. J.

\section{Manuscript Info}

Manuscript History

Received: 19 November 2016

Final Accepted: 21 December 2016

Published: January 2017

Key words:-

Railway accidents, pedestrians in rail deaths, pattern of railway deaths, comparison of patterns ,Amputation, Fractures.

\section{Abstract}

Background: The purpose of all accident investigations is to establish the cause of the incident. This information will be sought for a number of reasons which may overlap. The victims or their families may want to see what can be done to prevent recurrence. The patterns of injuries in railway track deaths may vary according to the position of the person or the different situations when struck. In forensic literature only few systematic studies of the respective injury pattern are available. In many instances the forensic pathologists are asked to reconstruct the event after medicolegal autopsy. Hence an attempt is made to study the pattern of injury in pedestrians involved in railway track incidences with relative position of victim and train so that this study may help the forensic pathologist to reconstruct the events and rule out foul play.

Materials and methods: A cross sectional study of all railway track deaths brought for medicolegal autopsy at Thiruvananthapuram Medical College, Kerala, from $1^{\text {st }}$ March 2010 to $28^{\text {th }}$ February 2011 were analyzed. A total of 104 cases of railway track deaths were studied excluding cases with advanced decomposition. Data regarding nature of incidents were collected from the Kerala Police Form 102 (KPF 102), investigating officers and relatives. Clinical case records were studied in treated cases. A meticulous external and internal examination was made and the details regarding nature, dimensions and location of injury was entered in a proforma. The data were entered in MS Excel and statistical analysis was done.

Results: Among 104 cases of railway accidents in the study period 17 (16.3\%) cases were those with history of hit by train while they were walking along the side of or through the track (GROUP I) and 34 $(32.7 \%)$ cases were those with history of crossing the track (GROUP II). All the cases showed external injuries. In all cases of Group I, there was lacerated wound on the head, and in $82.4 \%$ external injury was present on the face also. Among these, 6 cases (35.3\%) showed crushed lacerated wounds on the head and face. In 14 cases $(82.4 \%)$ there was skull fracture. Facial bone was fractured in $52.9 \%$ of cases and showed intracranial haemorrhages associated with skull fracture. Injury to brain was seen in $17.6 \%$ of cases. Two $(11.8 \%)$ cases showed fatal neck injury, one was a case with decapitation injury and the other showed fracture of the cervical spine with contusion of the cord. Nine cases $(52.9 \%)$ showed injury to chest and 8 among them

Corresponding Author:-.Dr. Sreelekshmi. J. Address:-.Junior resident medical officer, Department of forensic medicine and toxicology Govt.T.D 
(47\%) showed injury to abdomen also.. Thoracic spine was fractured in $23.5 \%$ of cases. Transection had occurred in 2 cases (11.8\%) .

The most prominent injury in group II was lacerated wound (91\%). Head and face were injured in 31 cases (91\%). In this, 9 cases (26.5\%) showed fracture fragmentation of skull bone with extrusion of the brain. Skull fracture was seen in 18 cases (52.9\%). Out of which, Intra cranial haemorrhage was present in 8 cases $(23.5 \%)$ and another $2.9 \%$ showed isolated intra cranial haemorrhage. Brain showed injury in 9 cases (26.5\%).Decapitation was seen in 6 cases (17.6\%). In 7 cases $(20.5 \%)$ soft tissue injury with cervical spine fracture was seen. One case $(2.9 \%)$ showed only soft tissue injury on the neck region. Chest and abdomen were injured in 38.2\% cases and $32.4 \%$ showed chest injury alone. Abdominal injury alone was present in one case, that too was a transection injury. In 20 cases $(58.8 \%)$ ribs were fractured. Sternum and thoracic spine were fractured in $4(11.8 \%)$ and $8(23.5 \%)$ cases respectively. The chest viscera were injured in 10cases (29.4\%) .Lumbar spine was fractured in $2.9 \%$ of cases.

Conclusion: Head injuries were common in cases with history of crossing the track. Cases with history of walking along the side of or through the train showed characteristics pattern of lacerated wound with fracture on the back of head. Transection injuries were common in cases with history of walking along the track and while crossing the track. In cases with history of crossing the track, most of the injuries were distributed on the upper part of the body. In the case where hit occurring in the upright position, lacerated wounds can be caused on the upper part of the body due to hitting against the projecting parts of train like buffer head, hand rail, or platform in front of loco engine.

Copy Right, IJAR, 2016,. All rights reserved.

\section{Introduction:-}

\section{Background:-}

Large number of people use some form of mass transportation systems such as trains, buses or aero planes, and accidents involving these are disastrous. Being a huge system of transportation, railway is an agent causing accidents during operations and any type of trauma may be seen in this. It traverses the length and breadth of the country covering 6909 stations over a total route length of more than $63273 \mathrm{~km}$ (39350 miles) through both urban and rural areas ${ }^{1}$. Railway deaths are usually because of a person trying to cross the track/collision between trains, automobile accident in unmanned crossings, passengers who hang out of doors $\&$ are hit by trees/poles or during outbreak of fire. ${ }^{2}$ In the absence of case history it is difficult to distinguish between, accident/Suicidal death or criminal violence. ${ }^{3}$ Railway wheel mark. dirt\& grease contamination, pattern of injuries over the body deserve careful observation to rule out criminal violence. ${ }^{4}$ The patterns of injuries in railway track deaths may vary according to the position of the person or the different situations when struck. The victims or their families may want to know why they were injured or killed; the regulatory authorities may wish to fix the responsibility and the safety authorities will want to see what can be done to prevent recurrence ${ }^{5}$. This study may help the forensic pathologist to a considerable extent in their proceedings in suspicious cases of railway incidences.

\section{Aims \& Objectives:-}

1. To find out the pattern of injuries among pedestrians involved in accidents while walking along the side, through or crossing the railway tracks.

2. To compare the pattern of injuries in pedestrians involved in accidents while walking along the side or through tracks with those during crossing the railway tracks.

\section{Materials And Methods:-}

A cross sectional study of all railway track deaths brought for medicolegal autopsy at Thiruvananthapuram Medical College, Kerala, from $1^{\text {st }}$ March 2010 to $28^{\text {th }}$ February 2011 were analyzed. A total of 104 cases of railway track 
deaths were studied excluding cases with advanced decomposition. Data regarding nature of incidents were collected from the Kerala Police Form 102 (KPF 102),investigating officers and relatives. Clinical case records were studied in treated cases. A meticulous external and internal examinations was made and the details regarding nature, dimensions and location of injury was entered in a proforma. From the history given by the informant, the victims were classified in to two groups. Group I was persons walking along the side or through the track and group II was persons crossing the railway track. The data were entered in MS Excel and statistical analysis was done.

\section{Results:-}

\section{GROUP I- WALKING ALONG THE SIDE OF OR THROUGH THE TRACK}

In the study population (104 cases) $16.3 \%$ of victims were those with history of hit by train while they were walking along the side of or through the track. All the cases showed external injuries. These cases showed high rate of incidence of abrasion and lacerated wounds (TABLE 1). In all the cases there was lacerated wound on the head, and in $82.4 \%$ external injury was present on the face also. Among these, 6 cases $(35.3 \%)$ showed crushed lacerated wounds on the head and face. In 14 cases $(82.4 \%)$ there was skull fracture. Facial bone was fractured in $52.9 \%$ of cases and showed intracranial haemorrhages associated with skull fracture. Injury to brain was seen in $17.6 \%$ of cases. In this group only $2(11.8 \%)$ cases showed fatal neck injury, one was a case with decapitation injury and the other showed fracture of the cervical spine with contusion of the cord. Nine cases (52.9\%) showed injury to chest and 8 among them (47\%) showed injury to abdomen also. Rib fractures were present in $52.9 \%$. Associated lung injury was seen in $29.4 \%$ of cases. Thoracic spine was fractured in $23.5 \%$ of cases. Among the abdominal organs liver was the frequently affected organ. Laceration of liver was seen in $17.6 \%$ of cases. Transection had occurred in 2 cases $(11.8 \%)$ at the level of abdomen with eventration of viscera in one case. Traumatic amputation of the upper limb occurred in one case and in the lower limb the frequency was 17.6\% (FIGURE 1 ).

\section{GROUP II- WHILE CROSSING THE RAIL TRACK}

Of the 104 cases studied $32.7 \%$ occurred while crossing the rail track. All the cases showed external injuries. Among the external injuries the most prominent group was lacerated wound (91\%)(TABLE1). Head and face were injured in 31 cases $(91 \%)$. In this, 9 cases $(26.5 \%)$ showed fracture fragmentation of skull bone with extrusion of the brain. Skull fracture was seen in 18 cases (52.9\%). Out of which, Intra cranial haemorrhage was present in 8 cases (23.5\%) and another $2.9 \%$ showed isolated intra cranial haemorrhage. Brain showed injury in 9 cases (26.5\%).Decapitation was seen in 6 cases (17.6\%). In 7 cases (20.5\%) soft tissue injury with cervical spine fracture was seen. One case $(2.9 \%)$ showed only soft tissue injury on the neck region. Among the 34 cases analyzed, chest and abdomen were injured in $38.2 \%$ cases and $32.4 \%$ showed chest injury alone. Abdominal injury was present in one case, that too was a transection injury. In 20 cases (58.8\%) ribs were fractured. Sternum and thoracic spine were fractured in $4(11.8 \%)$ and $8(23.5 \%)$ cases respectively. The chest viscera were injured in 10cases $(29.4 \%)$. The chest structure most commonly involved was rib (58.8\%) and among the thoracic viscera, the organ which showed a high frequency of injury was lung (32.4\%). Among the abdominal organs liver (20.5\%), intestine and mesentery (14.7\%), spleen (11.8\%) and kidneys $(8.8 \%)$ were the organs frequently injured. Liver showed the highest frequency. Lumbar spine was fractured in $2.9 \%$ of cases. In 2 cases $(5.8 \%)$ there was transection through the abdomen, with one showing extrusion of abdominal viscera. In one case there was transection through the pelvic region with missing of pelvic viscera. Excluding this case another 6 cases (17.6\%) also showed pelvic bone fracture. Frequency of traumatic amputation of the limbs was higher in this group. $23.5 \%$ of cases showed amputations in the upper limbs and $5.8 \%$ in lower limbs. In the upper limbs multiple sites were involved in $11.7 \%$ cases and in lower limb only one case showed amputation at multiple sites. In four cases the same limb showed fracture at multiple sites and amputation

Excluding the sites of amputation, incidence of fracture was also high in this group. In 8 cases (23.5\%) upper limb showed fracture at single site and in 7 cases $(20.5 \%$ ) at multiple sites (FIGURE 2). In lower limbs, fracture of a single bone was seen in $23.5 \%$ of cases and more than one bone is fractured in $5.8 \%$ of cases. In one case amputation of lower limb was seen on one side and fracture of limb bones on the opposite side. If the person was hit by train at the moment of entering into the track, it will cause injury to the preceding parts of the body. In 21 $(61.76 \%)$ cases the injuries were concentrated on the upper parts of the body especially on the head, shoulder and upper limbs. In this group 6 cases (17.6\%) showed decapitation injury. 


\section{Discussion:-}

An attempt was made to compare and correlate the pattern of injury derived by the study in accordance with the nature of incidence and the history provided by the informant.

\section{Cases with history of walking along the side of or through the track.}

Seventeen cases $(16.3 \%)$ comprise this group. Abrasions were mostly distributed in the upper limbs (88.2\%) and lower limbs (70.5\%). This was in agreement in study done by Ammamulla ${ }^{6}$ and Pathak et al ${ }^{7}$. Lacerated wounds were seen in all cases in the head region followed by lower limbs in $64.7 \%$ of cases. The chest region was free of lacerated wounds. Contusions were also frequent on the head (35.2\%). Decapitation was present only in a single case $(5.8 \%)$. The type of injury which dominated was lacerated wound involving the head region. Transection injury was present in 2 cases (11.8\%); one at the level of abdomen and the other at the pelvic region (5.8\%) each. Traumatic amputations and fracture of limbs showed high rates of incidence. Incidence of fracture was very high when compared to the incidence of amputation.

Cases with history of crossing the rail track:

The study populations came under this group was $32.7 \%$. This was the largest group. All the victims gave a history of tresspassing on to the Railway track. Using the railway track as a short cut to cross to the other side, to reach the other platform, to reach the railway station or to reach home is a common practice which is endangering the safety of humans and railway track. This is in agreement with the study done by Ramesh wasnik ${ }^{8}$. Laceration of head $(91 \%)$ was the most frequent external injury seen among this group. In all the cases there was fracture of the skull boneas observed in other studies ${ }^{9,10}$. In $26.4 \%$ of cases there were contusions and lacerated wounds with fracture fragmentation of the skull bones and in these cases the brain was found extruded. Membrane haemorrhage was present in $26.5 \%$ of cases.

Fracture of the skull bone was seen in 14 cases $(82.3 \%)$. Facial bones were fractured in $52.9 \%$ of the cases. Intracranial haemorrhages were present in 5 cases $(29.4 \%)$; subarachnoid haemorrhage was present in $(29.4 \%)$ of cases and subdural haemorrhage in $11.8 \%$ of cases. Brain injury was present in $17.6 \%$ of cases. In $58.8 \%$ of cases there was rib fracture which was the most commonly affected structure on the chest. There were associated injuries to other chest structures and chest viscera in $29.4 \%$ of cases. Sternum alone was fractured in $11.8 \%$ of cases.

Transection of trunk was present in $8.8 \%$ of cases; $5.9 \%$ of cases at the level of abdomen and $2.9 \%$ cases through the pelvic region due to run over. This is in agreement with V.V pillay ${ }^{11}$.Limb fracture was common in this group which showed upper limb fracture in $48.5 \%$ cases and the lower limbs fracture in $41 \%$ cases. Amputations were also frequently seen $23.5 \%$ in upper limb and $5.8 \%$ in lower limbs at single site and $11.7 \%$ in upper limbs and $2.9 \%$ in lower limbs at multiple sites ).

\section{COMPARISON OF INJURY PATTERNS AMONG THE ABOVE GROUPS}

The cases in these groups involved pedestrians who were hit in an upright position. Hence the injuries in these two groups should show a similar pattern. When the injury pattern of two groups were compared pedestrians with history of crossing the track showed more extensive injuries than the ones who were walking along the side or through the track(TABLE 2)In Group I, head was involved in $82.3 \%$, upper limbs in $41 \%$ \& lower limbs in $47 \%$. In Group II, the head was involved in $91 \%$ and the upper and lower limbs showed a frequency of $47 \%$ and $32.4 \% . A$ significant difference was observed in the distribution of injuries to neck, chest and lower limbs. In Group II victims, neck was involved in $38.2 \%$ cases while in the other group it was only $5.8 \%$. The basic reason could be the increased chance of upper part of the body which is proceeding while climbing up to the rail track to cross it. In this group the lower limbs were less involved (32.4\%). There is more chance of being thrown out of the track when the train hit the upper part of the body. The study by Dr.Kishorkumar in 2005 also showed similar values ${ }^{12}$.

In the case where hit occurring in the upright position, lacerated wounds can be caused on the upper part of the body due to hitting against the projecting parts of train like buffer head, hand rail, or platform in front of loco engine. If the victim was walking through the side of the track, the hand rail may hit against the shoulder or back of head causing characteristic lacerated wounds on these parts. This is in agreement with Sahoo et al ${ }^{13}$.

The frequency of traumatic amputation of upper limbs and lower limbs in Group I was 5.8\% and $17.6 \%$ respectively ,while in the other group the rates were $23.5 \%$ and $5.8 \%$ respectively. This also showed a reduced involvement of the lower parts of body while crossing the track. In Group. I and II, the person might have been hit in the upright 
position. The chance of falling in the track and run over by the train is more. In cases where hit can occur in the upright position, lacerated wound can be caused on the upper part of the body due to hitting against the projecting parts of train like buffer head, hand rail, or platform in front of loco engine as discussed by Umadathan ${ }^{14}$.

If the train hit the person while at the middle of the track, he may get pushed down and the degree of mutilation will be high. Injuries to head and limbs followed the similar pattern as the one which is observed in cases with history of walking along the side of or through the track. While crossing the track, train is hitting usually on the side of the body and in the other case it is hitting on the back or in the front aspect. In both the cases the victim is in the upright position.

Table 1:- Distribution of external injuries among the pedestrians walking along the side or through the track (Group $\mathrm{I}, \mathrm{n}=17$ ) \&crossing the track (Group II, $\mathrm{n}=34$ ).

\begin{tabular}{|l|l|l|l|l|l|l|l|l|}
\hline \multirow{2}{*}{ Injury } & Groups & $\begin{array}{l}\text { Head } \\
\text { (n) }\end{array}$ & $\begin{array}{l}\text { Neck } \\
\text { (n) }\end{array}$ & $\begin{array}{l}\text { Upper } \\
\text { limbs } \\
(\mathrm{n})\end{array}$ & $\begin{array}{l}\text { Chest } \\
(\mathrm{n})\end{array}$ & $\begin{array}{l}\text { Abdomen } \\
(\mathrm{n})\end{array}$ & $\begin{array}{l}\text { Pelvic } \\
\text { region } \\
(\mathrm{n})\end{array}$ & $\begin{array}{l}\text { Lower } \\
\text { limbs } \\
(\mathrm{n})\end{array}$ \\
\hline \multirow{2}{*}{ Abrasion } & Group I & $8(47.1)$ & $1(5.8)$ & $12(70.6)$ & $11(64.7)$ & $10(58.8)$ & $4(23.5)$ & $15(88.2)$ \\
\cline { 2 - 9 } & Group II & $14(41.2)$ & $4(11.8)$ & $24(70.6)$ & $13(38.2)$ & $9(26.4)$ & $1(2.9)$ & $26(76.4)$ \\
\hline \multirow{2}{*}{ Contusion } & Group I & $6(35.3)$ & $0(0.0)$ & $1(5.8)$ & $0(0.0)$ & $1(5.8)$ & $0(0.0)$ & $3(17.6)$ \\
\cline { 2 - 9 } & Group II & $11(32.4)$ & $1(2.9)$ & $2(5.8)$ & $2(5.8)$ & $2(5.8)$ & $0(0.0)$ & $1(2.9)$ \\
\hline $\begin{array}{l}\text { Abraded } \\
\text { contusion }\end{array}$ & Group I & $0(0.0)$ & $1(5.8)$ & $1(5.8)$ & $1(5.8)$ & $0(0.0)$ & $0(0.0)$ & $0(0.0)$ \\
\cline { 2 - 9 } $\begin{array}{l}\text { Lacerated } \\
\text { wound }\end{array}$ & Group II & $2(5.8)$ & $1(2.9)$ & $5(14.7)$ & $2(5.8)$ & $2(5.8)$ & $1(2.9)$ & $1(2.9)$ \\
\cline { 2 - 9 } & Group I & $17(100.0)$ & $1(5.8)$ & $9(52.9)$ & $0(0.0)$ & $4(23.5)$ & $4(23.5)$ & $11(64.7)$ \\
\hline
\end{tabular}

Table 2:-Distribution of pedestrians with injury according to body part affected and in different railway injury groups(Groups I and II)

\begin{tabular}{|l|l|l|l|l|l|l|}
\hline $\begin{array}{l}\text { Group } \\
(\mathrm{N}=51)\end{array}$ & $\begin{array}{l}\text { Head } \\
\mathrm{n}(\%)\end{array}$ & $\begin{array}{l}\text { Neck } \\
\mathrm{n}(\%)\end{array}$ & $\begin{array}{l}\text { Chest } \\
\mathrm{n}(\%)\end{array}$ & $\begin{array}{l}\text { Abdomen } \\
\mathrm{n}(\%)\end{array}$ & $\begin{array}{l}\text { Upper limb } \\
\mathrm{n}(\%)\end{array}$ & $\begin{array}{l}\text { Lower limb } \\
\mathrm{n}(\%)\end{array}$ \\
\hline Group I $(\mathrm{n}=17)$ & $14(82.3)$ & $2(11.8)$ & $9(52.9)$ & $8(47.0)$ & $7(41.0)$ & $8(47.0)$ \\
\hline Group II $(\mathrm{n}=34)$ & $31(91.0)$ & $13(38.2)$ & $24(70.5)$ & $14(41.0)$ & $18(52.9)$ & $11(32.4)$ \\
\hline
\end{tabular}


Figure 1:- Level of amputations among pedestrians with railway injuries

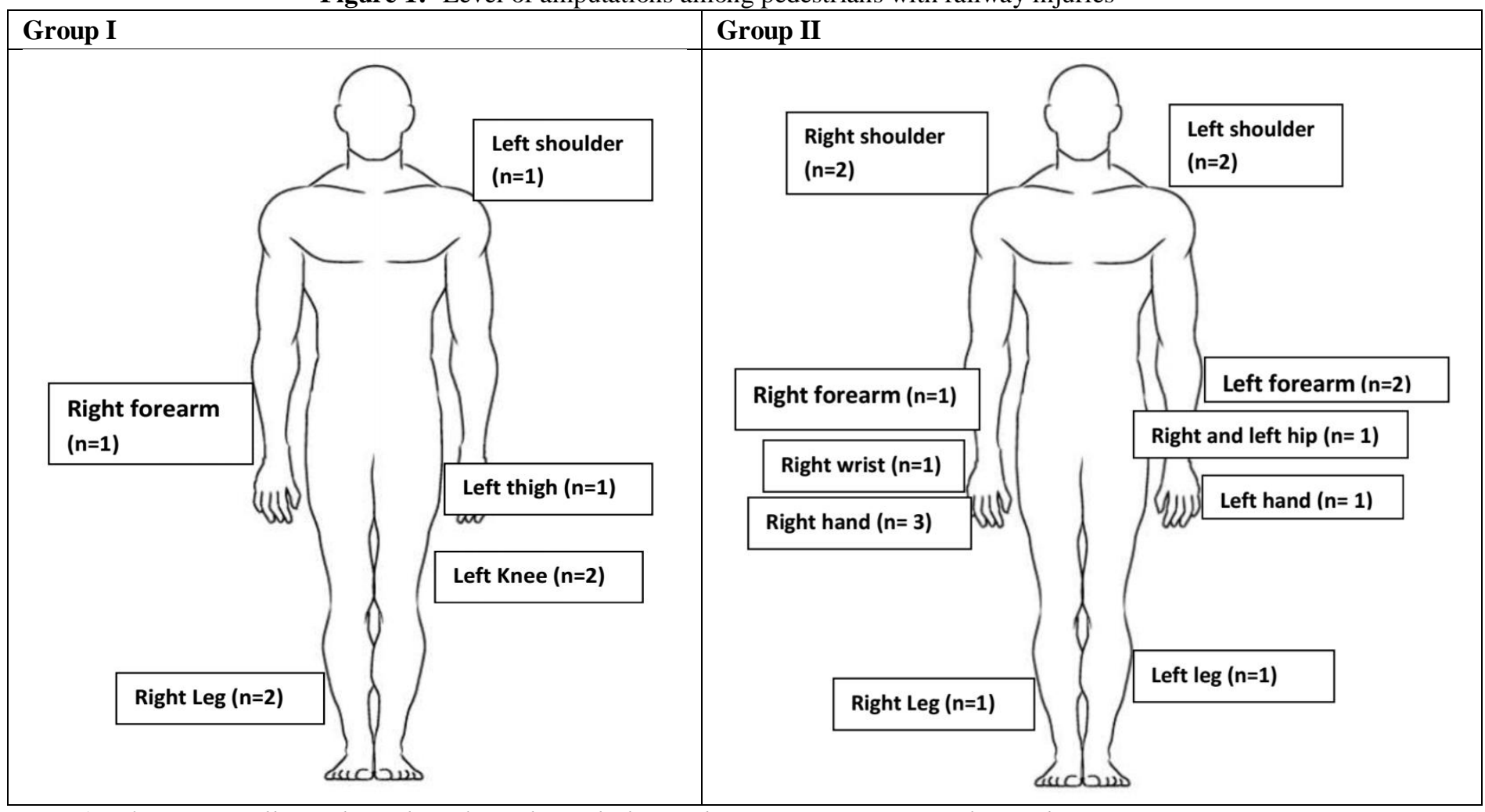

*pedestrians walking along the side or through the track (Group I) \& crossing the track (Group II). 
Figure 2: - Level of fractures in pedestrians with railway injuries

\begin{tabular}{|l|l|l|}
\hline Group I & Left shoulder ( $\mathrm{n}=1)$ \\
\hline Right elbow ( $\mathrm{n}=1)$ \\
(n=4)
\end{tabular}

\section{Conclusion:-}

High frequency of head injury was seen in cases with history of crossing the track (91\%). Cases with history of walking along the side of or through the train showed characteristics pattern of lacerated wound with fracture on the back of head. Transection injuries were common in cases with history of walking along the track and while crossing the track. In cases with history of crossing the track, injury to lower limbs were less. Most of the injuries were distributed on the upper part of the body. In the case where hit occurring in the upright position, lacerated wounds can be caused on the upper part of the body due to hitting against the projecting parts of train like buffer head, hand rail, or platform in front of loco engine. To conclude, the causation of majority of instances of railway track deaths are due to adult male trespassers who take short cut routes by walking along the railway tracks to reach their destinations and crossing the track carelessly.

\section{Acknowledgements:-}

We extend our sincere gratitude to Dr. P. Rema (Professor \& Head of The Department of Forensic Medicine, Trivandrum) and all other teachers \& faculties of Trivandrum medical college for the guidance, valuable and inspiring sense of communications and interactions in this study.

\section{Bibliography:-}

1. Rao.M.A, Indian Railways. India the land and the people, National Book Trust India.

2. ApurbaNandy (2010). Principles of forensic medicine including toxicology ( $3^{\text {rd }}$ edn) New Central Book agency, Howrah: 473-474.

3. Lerer L.B \&matzopolulos R.G (1997) fatal railway injuries in cape town south Africa AM.J Forensic Medicine \& Pathology 19, 144-7.

4. SarveshTandon, Ajay aggarwal, Sharma KL P.S Suicide Simulating homicide - A Railway track mystery, a case report JKAMLS 2001, 10(3): 60-63.

5. RudramD, Determination of cause; over view.The Forensic Science Service, London, Encyclopedia of Forensic Medicine, Volume 2 Academic press 
6. Ammamullah S. Railway Death in Jammu \& Kashmir. Medical News Medicine \& Law, 1983; 101-105.

7. PathakA, Barai P, Mahajan AK, Rathod B, Desai KP, Basu S. Risking Limbs and Life - Railway fatalities in Vadodara: (A Retrospective Study). Journal of Forensic Medicine and Toxicology, 2009, Volume 26, Issue 1, Print ISSN: 0971-1929.

8. Ramesh NanajiWasnik. Analysis of Railway Fatalities in Central India. J Indian Acad Forensic Med, 32(4)

9. Sabale PR, Mohite SC. Railway Fatalities in South West Mumbai. Medico-Legal Update - An International Journal, 2010; Volume 10, Issue 1, Print ISSN: 0971-720X.

10. Mohanty MK, Panigrahi MK, Mohanty S, Patnaik KK. Death due to traumatic railway injury. Med Sci Law, 2007; 47: 156-160.

11. V.V pillay . Textbook of forensic medicine and toxicology, 17 th edition : 185

12. Kishorekumar. B pattern of injuries in Railway track death submitted to the University of Calicut for MD Forensic Medicine examination 2005

13. Sahoo, P.C. Kar, S.M., Dash B.K., "Pattern of injuries in Railway deaths a retrospective study", 4th medicolegal 4. Basu R, Bose TK. Batabyal S, Paul PB, Railway Fatalities bulletin- Forensicon, 1998, pp 71-5.

14. B.Umadathan.Forensicmedicine;CBS publishers and distributors pvtltd;newdelhi, 1st ed $2011: 192$ 